\title{
The burden of injury in China, 1990-2017: findings from the Global Burden of Disease Study 2017
}

Duan Leilei*, Ye Pengpeng*, Juanita A Haagsma, Jin Ye, Wang Yuan, Er Yuliang, Deng Xiao, Gao Xin, Ji Cuirong, Wang Linhong, Marlena S Bannick, W Cliff Mountjoy-Venning, Caitlin N Hawley, Zichen Liu, Mari Smith, Spencer L Jamest, Theo Vost, ChristopherJ L Murray

\section{Summary}

Background A comprehensive evaluation of the burden of injury is an important foundation for selecting and formulating strategies of injury prevention. We present results from the Global Burden of Diseases, Injuries, and Risk Factors Study (GBD) 2017 of non-fatal and fatal outcomes of injury at the national and subnational level, and the changes in burden for key causes of injury over time in China.

Methods Using the methods and results from GBD 2017, we describe the burden of total injury and the key causes of injury based on the rates of incidence, cause-specific mortality, and disability-adjusted life years (DALYs) in China estimated using DisMod-MR 2.1. We additionally evaluated these results at the provincial level for the 34 subnational locations of China in 2017, measured the change of injury burden from 1990 to 2017, and compared age-standardised DALYs due to injuries at the provincial level against the expected rates based on the Socio-demographic Index (SDI), a composite measure of development of income per capita, years of education, and total fertility rate.

Findings In 2017, in China, there were $77 \cdot 1$ million (95\% uncertainty interval [UI] 72 $5-81 \cdot 6)$ new cases of injury severe enough to warrant health care and 733517 deaths (681254-767006) due to injuries. Injuries accounted for $7.0 \%$ $(95 \%$ UI $6 \cdot 6-7 \cdot 2)$ of total deaths and $10 \cdot 0 \%(9 \cdot 5-10 \cdot 5)$ of all-cause DALYs in China. In 2017, there was a three-times variation in age-standardised injury DALY rates between provinces of China, with the lowest value in Macao and the highest in Yunnan. Between 1990 and 2017, the age-standardised incidence rate of all injuries increased by 50.6\% (95\% UI 46 - 6-54 -6) in China, whereas the age-standardised mortality and DALY rates decreased by $44 \cdot 3 \%(41 \cdot 1-48 \cdot 9)$ and $48 \cdot 1 \%(44 \cdot 6-51 \cdot 8)$, respectively. Between 1990 and 2017, all provinces of China experienced a substantial decline in DALY rates from all injuries ranging from $16 \cdot 3 \%(3 \cdot 1-28 \cdot 6)$ in Shanghai and $60 \cdot 4 \%(53 \cdot 7-66 \cdot 1)$ in Jiangxi. Agestandardised DALY rates for drowning; injuries from fire, heat and hot substances; adverse effects of medical treatments; animal contact; environmental heat and cold exposure; self-harm; and executions and police conflict each declined by more than $60 \%$ between 1990 and 2017.

Interpretation Between 1990 and 2017, China experienced a decrease in the age-standardised DALY and mortality rates due to injury, despite an increase in the age-standardised incidence rate. These trends occurred in all provinces. The divergent trends in terms of incidence and mortality indicate that with rapid sociodemographic improvements, the case fatality of injuries has declined, which could be attributed to an improving health-care system but also to a decreasing severity of injuries over this time period.

Funding Bill \& Melinda Gates Foundation.

Copyright (C) 2019 The Author(s). Published by Elsevier Ltd. This is an Open Access article under the CC BY 4.0 license.

\section{Introduction}

The burden of injury is a universal public health challenge that afflicts every country in the world, with cases distributed across all ages and both sexes. In China, rapid economic development, urbanisation, motorisation, ageing, and environmental and lifestyle changes over the past three decades have led to injury being reported as the fifth leading cause of death after malignant neoplasms, cerebrovascular disease, respiratory diseases, and heart attacks. ${ }^{1}$ Injuries cause an annual loss of 12.6 million years of productivity in China, more than for each of the respiratory, cardiovascular, infectious, and neoplastic disease groups. ${ }^{2}$ The direct medical cost of injury in China has been estimated to be about 65 billion Ren Min Bi or US $\$ 10$ billion per year. ${ }^{3}$ Consequently, injury is seen as a growing public health concern in China that could cause considerable economic expenditure.

Research and international cooperation in the fields of surveillance, intervention, education, promotion, and advocacy that target different types of injuries and highrisk populations has led to policies, regulations, and laws being introduced and implemented in various fields of injury prevention and control in China. ${ }^{4,5}$ However, there is still a lack of integrated data on the burden of injury across all injuries at both national and subnational levels. It is also increasingly of interest to measure the change in key injuries over time and to identify priority areas for injury prevention.

The goal of the Global Burden of Diseases, Injuries, and Risk Factors Study (GBD) 2017 was to incorporate

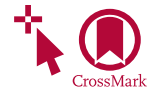
CrossMark

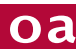

Lancet Public Health 2019; 4: e449-61

See Comment page e432

*Joint first authors.

†joint senior authors.

Division of Injury Prevention and Mental Health, National Center for Chronic and Noncommunicable Disease Control and Prevention, Chinese Center for Disease Control and Prevention, Beijing, China (D Leilei MD, Y Pengpeng MPH, J Ye MSc, WYuan PhD, EYuliang MPH, D Xiao MD, G Xin MD, J Cuirong MPH, W Linhong PhD); Center for Medical Decision Sciences, Department of Public Health, Erasmus Medical Center, Rotterdam, Netherlands (J A Haagsma PhD); and Institute for Health Metrics and Evaluation, University of Washington, Seattle, WA, USA (J A Haagsma MS Bannick BS,

WC Mountjoy-Venning BS C N Hawley MSPH, Z Liu BA, $M$ Smith MPA, S L James MD, ProfT Vos PhD, Prof (J L Murray PhD)

Correspondence to: DrWang Linhong, National Center for Chronic and Noncommunicable Disease Control and Prevention, Chinese Center for Disease Control and Prevention, Beijing 100050 , China

linhong@chinawch.org.cn 
Research in context

\section{Evidence before this study}

The burden of injuries in China is an important topic for public health planning and for contextualising economic trends and health interventions. We searched Ovid MEDLINE for articles published up to April 10, 2019, using compound search terms (appendix $\mathrm{p} 5$ ), with language restricted to English and Chinese. Previous research focused on the burden of injuries in China has been limited in scope in terms of including all injuries, estimating for all demographic groups and provinces, and modelling for a span of years. Past iterations of the Global Burden of Diseases, Injuries, and Risk Factors Study (GBD) have gradually increased the level of detail in terms of causes, locations, and demographic groups receiving estimations. GBD 2017 included subnational estimation for provinces of China for 30 mutually exclusive causes of injury. Given the rapid expansion of the economy in China over the past three decades, there was considerable interest in understanding the ramifications that such socioeconomic changes have had on the burden of injuries, given that the morbidity and mortality of certain injuries is thought to be affected by economic development. Past research focusing on the interaction between economic development and injury burden has revealed several factors that could affect injury incidence and mortality, such as the expansion of road systems, changing social patterns with migration of younger generations, and increasing educational access and attainment. However, to date, no studies have systematically measured the burden of injury in terms of morbidity and mortality at the province level in China over several years and for all age groups and both sexes.

\section{Added value of this study}

This study measures the burden of injury at both the national and provincial level in China in terms of incidence, cause-specific mortality, and disability-adjusted life years (DALYs). Additionally, it reports these measures for each of 30 mutually exclusive injury causes (except for select injuries that do not lead to death) for every age group and both sexes for the time period from 1990 to 2017. The results of the study are then interpreted on the basis of relevant historical and policy-related events from the past three decades that might have contributed to an evolving injury burden. The provision of such societal and historical context could help to explain the reasons for the dynamic trends observed for fatal and non-fatal results and how these trends might vary depending on the province.

Implications of all the available evidence

This study shows that although the incidence of injuries in China has increased with the expansion of the economy, the rates of cause-specific mortality and DALYs have declined. These observations suggest that the rapid socioeconomic development in China might have increased the risk of injury, but that improvements in health care or decreases in injury severity have led to large improvements in mortality and overall health loss. This study represents an important geographical research focus within the greater GBD project that might help to inform policy not only in China but also in other parts of the world that are experiencing economic growth and a shifting burden of injury.
See Online for appendix all available epidemiological data using a coherent measurement framework, standardised estimation methods, and transparent data sources to enable comparisons of health loss over time and across causes, age groups, sexes, and locations..$^{6-11}$ Here, we aim to provide an overview of the burden of injury in China in 2017, to measure the change in this burden between 1990 and 2017, and to explore the underlying factors influencing this change.

\section{Methods Overview}

In this analysis, we describe the burden of total injury and the key causes of injury based on the rates of incidence, cause-specific mortality, and disabilityadjusted life years (DALYs) in China. We present a detailed description of the top four causes of injury in terms of age-standardised DALY rates in 2017. The geographical units of analysis include 31 provinces in mainland China, Hong Kong special administrative region, Macao special administrative region, and Taiwan; all 34 locations will be referred to as provinces in the rest of the Article.

The GBD 2017 study design and methods specific to injury estimation have been described in extensive detail in existing GBD literature. ${ }^{6,10}$ An overview of GBD methods is provided in the appendix (pp 1-4). Here, we summarise key features of these methods.

This study complied with the Guidelines for Accurate and Transparent Health Estimates Reporting recommendations. ${ }^{12}$

\section{Case definitions}

In GBD 2017, there are 30 mutually exclusive and collectively exhaustive external cause of injury categories, with each category further divided among 47 mutually exclusive nature of injury categories. In this study, we report an aggregated version of this cause list. All subtypes of road injuries, for example, were combined into one road injuries cause. The definition of injury incidence and death was based on the International Classification of Diseases (ICD): codes E000-E999 in ICD-9 and chapters V to Y in ICD-10. ICD-9 codes 800-999 and ICD-10 chapters $S$ and $T$ were used for estimation of injury morbidity. Specific coding by injury is provided in the GBD 2017 literature. ${ }^{6,10}$

\section{Mortality}

For cause-specific mortality estimation, all data sources were first mapped to the GBD cause list of diseases and injuries. Second, garbage codes or ill-defined causes of 
deaths were redistributed to causes within the GBD cause hierarchy. Third, the GBD Cause of Death Ensemble model method was used to generate estimates by age, sex, location, year, and cause. Five main data sources from China were used across all causes of death: the China disease surveillance points (DSP) system, vital registration collected by the Chinese Center for Disease Control and Prevention (CDC), cancer registry data, and medical certification of causes of death for Macao and Hong Kong (the only data sources for Macao and Hong Kong). ${ }^{6}$ Years of life lost (YLLs) were estimated as the number of deaths from each cause in each age group multiplied by the remaining life expectancy at the age of death.

\section{Incidence, prevalence, and years lived with disability}

Measuring non-fatal health outcomes required combining two injury classification approaches. Injuries can be defined by cause and nature, where the cause of injury is the accident that led to a particular nature of injury. For example, for a fall that led to a traumatic brain injury, the fall would be considered the cause of injury and traumatic brain injury would be considered the nature of injury. In this study, we reported estimates by cause of injury.

The injuries estimation process used DisMod-MR 2.1, a Bayesian meta-regression tool, to produce injury incidence for different causes by location, year, age, and sex. The incidence of injury warranting inpatient admission and other types of care (eg, outpatient care including emergency department visits) was estimated separately. Second, the nature-of-injury category resulting in the largest burden for patients experiencing multiple injuries was selected through a hierarchy constructed according to patient-reported outcome measurement data as described in the GBD 2017 methods. ${ }^{10}$ Third, the proportions of incident cases in each combined cause-nature-of-injury category were estimated and then applied to cause of injury incidence obtained from the first step to estimate incidence of inpatient and outpatient injuries by cause and nature of injury. Fourth, short-term disability and average duration for each nature of injury category were estimated and short-term prevalence was derived from the multiplication of incidence and duration. Fifth, the proportion of cases with permanent disability for each nature of injury category was estimated and the ordinary differential equation solver used in DisMod-MR 2.1 was used to estimate the long-term prevalence for each cause-nature of injury from the incidence and long-term mortality risk in cases with long-term disability. Additional data sources used for the estimation of nonfatal health outcomes were the Chinese National Injury Surveillance System (NISS) and the China Zhuhai injury patient follow-up study. ${ }^{13,14}$

\begin{tabular}{|c|c|c|c|c|}
\hline & \multicolumn{2}{|l|}{ Deaths } & \multicolumn{2}{|l|}{ Incidence } \\
\hline & $\begin{array}{l}2017 \text { age-standardised } \\
\text { rates per } 100000\end{array}$ & $\begin{array}{l}\text { Percentage change in } \\
\text { age-standardised rates, } \\
\text { 1990-2017 }\end{array}$ & $\begin{array}{l}2017 \text { age-standardised } \\
\text { rates per } 100000\end{array}$ & $\begin{array}{l}\text { Percentage change in } \\
\text { age-standardised rates, } \\
1990-2017\end{array}$ \\
\hline All injuries & $45 \cdot 9(42 \cdot 9$ to $47 \cdot 8)$ & $-44 \cdot 3 \%(-48 \cdot 9$ to $-41 \cdot 1)$ & 5112 (4827 to 5410$)$ & $50 \cdot 6 \%(46.6$ to $54 \cdot 6)$ \\
\hline Transport injuries & $16.1(15.4$ to 16.8$)$ & $-23 \cdot 9 \%(-32 \cdot 7$ to $-17 \cdot 6)$ & 1099 (973 to 1239 ) & $82 \cdot 2 \%(73.7$ to 89.9$)$ \\
\hline Road injuries & $15 \cdot 6(14 \cdot 8$ to $16 \cdot 2)$ & $-21 \cdot 8 \%(-30 \cdot 7$ to $-14 \cdot 9)$ & $940(810$ to 1075$)$ & $113 \cdot 9 \%(103 \cdot 7$ to $123 \cdot 6)$ \\
\hline Other transport injuries & $0.6(0.5$ to 0.6$)$ & $-55 \cdot 9 \%(-63 \cdot 4$ to $-48 \cdot 0)$ & 160 (130 to 197$)$ & $-2 \cdot 8 \%(-8 \cdot 5$ to 4.5$)$ \\
\hline Unintentional injuries & $21.6(18.9$ to 22.9$)$ & $-40 \cdot 9 \%(-50 \cdot 9$ to $-35 \cdot 4)$ & 3635 (3391 to 3888 ) & $55 \cdot 5 \%(50 \cdot 7$ to $60 \cdot 3)$ \\
\hline Falls & $8.6(6.7$ to 9.5$)$ & $12 \cdot 8 \%(-23 \cdot 9$ to $33 \cdot 4)$ & 1477 (1288 to 1691$)$ & $113 \cdot 2 \%(104 \cdot 4$ to $123 \cdot 6)$ \\
\hline Drowning & $5 \cdot 1(4 \cdot 9$ to $5 \cdot 3)$ & $-65 \cdot 3 \%(-67 \cdot 5$ to $-62 \cdot 9)$ & 8 (7 to 10$)$ & $-17 \cdot 4 \%(-23 \cdot 8$ to $-10 \cdot 2)$ \\
\hline Fire, heat, and hot substances & $0.7(0.6$ to 0.8$)$ & $-64 \cdot 9 \%(-68 \cdot 7$ to $-51 \cdot 9)$ & 108 (87 to 133$)$ & $46 \cdot 0 \%(36 \cdot 7$ to $56 \cdot 2)$ \\
\hline Poisonings & $1.7(0.9$ to 2.0$)$ & $-20 \cdot 8 \%(-66 \cdot 3$ to $15 \cdot 3)$ & 56 (46 to 69$)$ & $48 \cdot 2 \%(36.5$ to $60 \cdot 6)$ \\
\hline Exposure to mechanical forces & $1 \cdot 9(1 \cdot 3$ to $2 \cdot 1)$ & $-24.4 \%(-65.0$ to -8.6$)$ & 797 (683 to 931$)$ & $85.5 \%$ (76.7 to $95 \cdot 4)$ \\
\hline Adverse effects of medical treatment & $0.4(0.4$ to 0.6$)$ & $-66 \cdot 5 \%(-73 \cdot 7$ to $-51 \cdot 5)$ & 506 (430 to 586$)$ & $64 \cdot 2 \%(56 \cdot 2$ to $72 \cdot 4)$ \\
\hline Animal contact & $0.2(0.1$ to 0.2$)$ & $-77 \cdot 7 \%(-82 \cdot 3$ to $-50 \cdot 7)$ & 232 (196 to 273$)$ & $-33 \cdot 3 \%(-36 \cdot 3$ to $-30 \cdot 0)$ \\
\hline Foreign body & $1.4(1.2$ to 1.5$)$ & $-50 \cdot 8 \%(-61 \cdot 6$ to $-44 \cdot 0)$ & 185 (162 to 208$)$ & $6 \cdot 2 \%(0.1$ to $12 \cdot 9)$ \\
\hline Environmental heat and cold exposure & $0.3(0.2$ to 0.4$)$ & $-75 \cdot 8 \%(-79 \cdot 1$ to $-63 \cdot 5)$ & 104 (86 to 125$)$ & $-8.8 \%(-13.9$ to -3.6$)$ \\
\hline Exposure to forces of nature & $0.0(0.0$ to 0.0$)$ & $-67 \cdot 4 \%(-67 \cdot 4$ to $-67 \cdot 4)$ & 2 (2 to 2 ) & $-67 \cdot 4 \%(-67 \cdot 4$ to $-67 \cdot 4)$ \\
\hline Other unintentional injuries & $1 \cdot 2(1.1$ to 1.2$)$ & $-2.7 \%(-8.9$ to 5.9$)$ & 161 (132 to 196$)$ & $11 \cdot 5 \%(5 \cdot 7$ to $17 \cdot 8)$ \\
\hline Self-harm and interpersonal violence & $8 \cdot 2(7 \cdot 8$ to $9 \cdot 1)$ & $-66 \cdot 7 \%(-69 \cdot 9$ to $-58 \cdot 1)$ & 376 (321 to 440$)$ & $-16 \cdot 6 \%(-22 \cdot 7$ to $-9 \cdot 0)$ \\
\hline Self-harm & $7 \cdot 2(6.8$ to 7.9$)$ & $-65 \cdot 6 \%(-68 \cdot 7$ to $-57 \cdot 6)$ & 29 (24 to 35) & $-39 \cdot 4 \%(-45 \cdot 1$ to $-33 \cdot 8)$ \\
\hline Interpersonal violence & $1.0(0.8$ to 1.3$)$ & $-71 \cdot 7 \%(-76 \cdot 5$ to $-59 \cdot 7)$ & 341 (287 to 403$)$ & $-4.5 \%(-10 \cdot 4$ to $1 \cdot 4)$ \\
\hline Conflict and terrorism & $0.0(0.0$ to 0.0$)$ & $-100 \cdot 0 \%(-100 \cdot 0$ to $-100 \cdot 0)$ & $0(0$ to 0$)$ & $-100 \cdot 0 \%(-100 \cdot 0$ to $-100 \cdot 0)$ \\
\hline Executions and police conflict & $0.0(0.0$ to 0.1$)$ & $-86 \cdot 8 \%(-89 \cdot 0$ to $-55 \cdot 3)$ & $6(5$ to 8$)$ & $-87 \cdot 1 \%(-89 \cdot 5$ to $-56 \cdot 3)$ \\
\hline
\end{tabular}




\begin{tabular}{|c|c|c|c|c|c|c|}
\hline & \multicolumn{2}{|l|}{ YLLs } & \multicolumn{2}{|l|}{ YLDs } & \multicolumn{2}{|l|}{ DALYs } \\
\hline & $\begin{array}{l}2017 \text { age-standardised } \\
\text { rates per } 1000000\end{array}$ & $\begin{array}{l}\text { Percentage change in } \\
\text { age-standardised rates, } \\
\text { 1990-2017 }\end{array}$ & $\begin{array}{l}2017 \text { age-standardised } \\
\text { rates per } 100000\end{array}$ & $\begin{array}{l}\text { Percentage change in } \\
\text { age-standardised rates, } \\
1990-2017\end{array}$ & $\begin{array}{l}2017 \text { age-standardised } \\
\text { rates per } 100000\end{array}$ & $\begin{array}{l}\text { Percentage change in } \\
\text { age-standardised rates, } \\
\text { 1990-2017 }\end{array}$ \\
\hline All injuries & 1893 (1798 to 1963 ) & $-55 \cdot 8 \%(-58.8$ to $-53 \cdot 4)$ & 580 (430 to 758 ) & $21.2 \%(14.9$ to 27.9$)$ & 2473 (2298 to 2679) & $-48 \cdot 1 \%(-51 \cdot 8$ to $-44 \cdot 6)$ \\
\hline Transport injuries & 724 (693 to 754) & $-35 \cdot 0 \%(-42 \cdot 0$ to $-29 \cdot 8)$ & 198 (141 to 268 ) & $32.1 \%(24.5$ to $40 \cdot 0)$ & 923 (855 to 996$)$ & $-27 \cdot 0 \%(-33 \cdot 9$ to $-21 \cdot 3)$ \\
\hline Road injuries & 699 (669 to 728$)$ & $-33 \cdot 3 \%(-40 \cdot 4$ to $-27 \cdot 7)$ & 155 (111 to 209) & $70 \cdot 2 \%(62 \cdot 1$ to $79 \cdot 1)$ & 854 (798 to 914) & $-25 \cdot 0 \%(-32 \cdot 5$ to $-18 \cdot 8)$ \\
\hline Other transport injuries & 25 (23 to 26$)$ & $-62 \cdot 0 \%(-67 \cdot 9$ to $-53 \cdot 7)$ & 44 (31 to 60$)$ & $-26 \cdot 3 \%(-30 \cdot 5$ to $-21 \cdot 6)$ & 69 (56 to 84$)$ & $-45 \cdot 1 \%(-51 \cdot 1$ to $-38 \cdot 5)$ \\
\hline Unintentional injuries & 872 (775 to 921) & $-58 \cdot 2 \%(-64 \cdot 5$ to $-54 \cdot 3)$ & 280 (196 to 384) & $27 \cdot 8 \%(19 \cdot 7$ to $36 \cdot 2)$ & 1152 (1017 to 1279) & $-50 \cdot 1 \%(-56 \cdot 8$ to $-44 \cdot 9)$ \\
\hline Falls & 209 (157 to 234$)$ & $-18 \cdot 9 \%(-50 \cdot 1$ to $-2 \cdot 3)$ & 154 (109 to 211$)$ & $67.6 \%(57.0$ to 78.5$)$ & 363 (288 to 433$)$ & $3 \cdot 8 \%(-25 \cdot 6$ to $18 \cdot 6)$ \\
\hline Drowning & 297 (283 to 312 ) & $-71 \cdot 4 \%(-73 \cdot 4$ to $-69 \cdot 2)$ & 3 (2 to 3$)$ & $-34 \cdot 7 \%(-39 \cdot 9$ to $-29 \cdot 5)$ & 300 (285 to 314$)$ & $-71 \cdot 3 \%(-73 \cdot 3$ to $-69 \cdot 1)$ \\
\hline $\begin{array}{l}\text { Fire, heat, and hot } \\
\text { substances }\end{array}$ & 23 (19 to 27$)$ & $-74 \cdot 8 \%(-78 \cdot 6$ to $-59 \cdot 2)$ & 25 (15 to 39) & $-18 \cdot 0 \%(-35 \cdot 6$ to $-0 \cdot 7)$ & 48 (38 to 63$)$ & $-60 \cdot 7 \%(-68 \cdot 7$ to $-44 \cdot 4)$ \\
\hline Poisonings & $72(40$ to 86$)$ & $-38.0 \%(-73 \cdot 0$ to $-9 \cdot 6)$ & $3(2$ to 4$)$ & $50 \cdot 4 \%(39 \cdot 3$ to $60 \cdot 9)$ & 74 (43 to 89) & $-36 \cdot 6 \%(-71 \cdot 6$ to $-8 \cdot 2)$ \\
\hline $\begin{array}{l}\text { Exposure to mechanical } \\
\text { forces }\end{array}$ & 91 (64 to 99) & $-35 \cdot 0 \%(-68 \cdot 9$ to $-23 \cdot 1)$ & 45 (31 to 66$)$ & $49.0 \%(37.6$ to $60 \cdot 8)$ & 136 (107 to 159$)$ & $-20 \cdot 1 \%(-53 \cdot 1$ to $-6 \cdot 9)$ \\
\hline $\begin{array}{l}\text { Adverse effects of medical } \\
\text { treatment }\end{array}$ & 18 (16 to 23$)$ & $-73 \cdot 3 \%(-79 \cdot 3$ to $-57 \cdot 6)$ & $5(3$ to 8$)$ & $64 \cdot 2 \%(56 \cdot 2$ to $72 \cdot 3)$ & 23 (20 to 28$)$ & $-67 \cdot 2 \%(-74 \cdot 6$ to $-49 \cdot 2)$ \\
\hline Animal contact & 6 (5 to 8$)$ & $-83 \cdot 1 \%(-86 \cdot 6$ to $-55 \cdot 1)$ & 5 (3 to 7$)$ & $-42 \cdot 7 \%(-45 \cdot 9$ to $-40 \cdot 0)$ & 11 (9 to 14$)$ & $-75 \cdot 3 \%(-80 \cdot 1$ to $-50 \cdot 9)$ \\
\hline Foreign body & 90 (78 to 99) & $-58.8 \%(-67.6$ to $-52 \cdot 1)$ & $12(8$ to 16$)$ & $-17 \cdot 2 \%(-23 \cdot 6$ to $-9 \cdot 6)$ & 101 (88 to 111$)$ & $-56 \cdot 2 \%(-65 \cdot 3$ to $-49 \cdot 8)$ \\
\hline $\begin{array}{l}\text { Environmental heat and } \\
\text { cold exposure }\end{array}$ & $8(5$ to 10$)$ & $-83 \cdot 6 \%(-86 \cdot 3$ to $-73 \cdot 5)$ & 15 (10 to 21$)$ & $-28 \cdot 6 \%(-34 \cdot 0$ to $-23 \cdot 2)$ & 23 (17 to 29) & $-67 \cdot 1 \%(-73.8$ to $-53 \cdot 4)$ \\
\hline $\begin{array}{l}\text { Exposure to forces of } \\
\text { nature }\end{array}$ & $2(2$ to 2$)$ & $-67 \cdot 4 \%(-67 \cdot 4$ to $-67 \cdot 4)$ & 2 (2 to 3$)$ & $188 \cdot 0 \%(143 \cdot 9$ to $235 \cdot 7)$ & $4(4$ to 5$)$ & $-36 \cdot 4 \%(-42 \cdot 9$ to $-28 \cdot 3)$ \\
\hline $\begin{array}{l}\text { Other unintentional } \\
\text { injuries }\end{array}$ & $57(54$ to 60$)$ & $-14.8 \%(-20 \cdot 0$ to $-7 \cdot 5)$ & $11(8$ to 16$)$ & $-12 \cdot 5 \%(-18 \cdot 8$ to $-6 \cdot 3)$ & 68 (63 to 73$)$ & $-14 \cdot 4 \%(-18 \cdot 9$ to $-8 \cdot 2)$ \\
\hline $\begin{array}{l}\text { Self-harm and } \\
\text { interpersonal violence }\end{array}$ & 297 (280 to 335$)$ & $-72 \cdot 7 \%(-75 \cdot 3$ to $-64 \cdot 8)$ & 102 (77 to 133$)$ & $-6 \cdot 9 \%(-11 \cdot 4$ to $-3 \cdot 2)$ & 399 (367 to 442) & $-66.7 \%(-69.9$ to $-58 \cdot 9)$ \\
\hline Self-harm & 243 (229 to 273$)$ & $-71 \cdot 9 \%(-74 \cdot 4$ to $-64 \cdot 7)$ & 2 (2 to 3$)$ & $-52.7 \%(-57 \cdot 9$ to $-46 \cdot 9)$ & 246 (232 to 275$)$ & $-71 \cdot 8 \%(-74 \cdot 3$ to $-64 \cdot 7)$ \\
\hline Interpersonal violence & 51 (46 to 71$)$ & $-74 \cdot 6 \%(-78 \cdot 5$ to $-63 \cdot 8)$ & $97(73$ to 128$)$ & $-4 \cdot 4 \%(-8 \cdot 5$ to $-1 \cdot 1)$ & 148 (122 to 184$)$ & $-51 \cdot 0 \%(-57 \cdot 6$ to $-40 \cdot 7)$ \\
\hline Conflict and terrorism & $0(0$ to 0$)$ & $-100 \cdot 0 \%(-100 \cdot 0$ to $-100 \cdot 0)$ & $0(0$ to 0$)$ & $-12 \cdot 0 \%(-25 \cdot 7$ to $2 \cdot 3)$ & $0(0$ to 0$)$ & $-45 \cdot 5 \%(-56 \cdot 6$ to $-31 \cdot 6)$ \\
\hline $\begin{array}{l}\text { Executions and police } \\
\text { conflict }\end{array}$ & 3 (2 to 3$)$ & $-87 \cdot 4 \%(-89 \cdot 6$ to $-56 \cdot 6)$ & 2 (1 to 3 ) & $-15 \cdot 3 \%(-29 \cdot 4$ to $16 \cdot 4)$ & 5 (4 to 6$)$ & $-79 \cdot 7 \%(-83 \cdot 3$ to $-47 \cdot 3)$ \\
\hline
\end{tabular}

Years lived with disability (YLDs) were then calculated by multiplying prevalence by a disability weight reflecting the magnitude of the health loss associated with an outcome after correction for comorbidity with other non-fatal diseases.

\section{DALYs}

DALYs are the sum of YLLs and YLDs as estimated in GBD 2017 for each cause, location, age group, sex, and year. ${ }^{7}$ A DALY essentially represents 1 lost year of healthy life. The sum of DALYs in a population approximates the gap between the population's present health status and an ideal scenario where the entire population has lived to an advanced age, free of disease.

\section{Socio-demographic Index}

The Socio-demographic Index (SDI) is a summary measure ranging from 0 to 1 that estimates the position of each GBD location on a spectrum of socioeconomic development. SDI is calculated using an equal weighting of lag-distributed income per capita, average years of education in the population older than 15 years of age, and total fertility rate in women younger than 25 years of age. The SDI for China in 2017 was $0 \cdot 71$, whereas at the province level, SDI varied from 0.47 to 0.86 . Globally, this placed China in the high-middle SDI quintile, with province-level SDI values varying from low-middle to high quintiles on a global scale.

\section{Uncertainty analysis}

We applied the same technique for propagating uncertainty as used elsewhere in the GBD study design. The distribution of every step in the computation process was stored in 1000 draws that were used for every step in the computational process. The distributions were determined from the sampling error from data inputs, the uncertainty of the coefficients from DisMod-MR 2.1, and the uncertainty of severity distributions and disability weights. Final estimates were computed using the mean estimate across 1000 draws, and 95\% uncertainty 
intervals (UIs) for each average were defined by the 25th and 975th values of the ordered 1000 estimate values.

\section{Role of the funding source}

The funder of the study had no role in study design, data collection, data analysis, data interpretation, or writing of the report. All authors had access to the data in the study and had final responsibility to submit for publication.

\section{Results}

In 2017, in China, there were 77.1 million (95\% UI $72 \cdot 5-81 \cdot 6)$ new cases of injury severe enough to warrant health care and 733517 deaths (681254-767006) due to injuries. Injuries accounted for $7 \cdot 0 \%$ (95\% UI 6.6-7.2) of total deaths and $10 \cdot 0 \%(9 \cdot 5-10 \cdot 5)$ of all-cause DALYs in China. Age-standardised rates of incidence, mortality, and DALYs for all injuries in 2017 were 5112 new cases (95\% UI 4827-5410) per $100000,45 \cdot 9$ deaths $(42 \cdot 9-47 \cdot 8)$ per 100000, and 2473 DALYs (2298-2679) per 100000 (tables 1, 2).

The age curves of incidence saw a gradual increase from early neonatal to 50-54 years of age for both sexes (30-34 years of age in males and 65-69 years of age in females), followed by a decline until 85-89 years of age, with a surge in incidence up to 95 years or older (figure 1). Death rates were relatively high in the first year of life, declining to low values from 1 to 74 years of age, followed by a steep rise from over the age of 75 years (figure 1). The age pattern of DALYs was much flatter than that of deaths after the first year of life because the YLL component of DALYs gives greater weight to deaths occurring in younger individuals and, to a lesser extent, the accumulation of cases with long-term consequences of the more severe injuries (figure 1). The agestandardised incidence, mortality, and DALY rates of all injuries combined were higher in males than in females (figure 1).

Across provinces, age-standardised incidence rates of all injuries varied from a low of 3152 (95\% UI 2972-3340) per 100000 in Gansu to a high of 9907 (9307-10468) in Beijing (table 3). The age-standardised death rate was lowest in Beijing (17 deaths [95\% UI 14-19] per 100000) and highest in Yunnan (74 deaths [63-86] per 100000). The age-standardised DALY rate of all injuries ranged from 1335 DALYs (1153-1556) per 100000 in Macao to 3733 DALYs (3256-4259) per 100000 in Yunnan (table 3).

Among different causes of injury in China, the four level 3 injuries with the highest age-standardised DALY rates were road injuries, falls, drowning, and selfharm, each with a distinct age pattern (figure 2; table 2).

Figure 1: Incidence, death, YLD, YLL, and DALY rates for all injuries by sex and age in China, 2017

YLD=year lived with disability. YLL=year of life lost. DALY=disability-adjusted life-year.
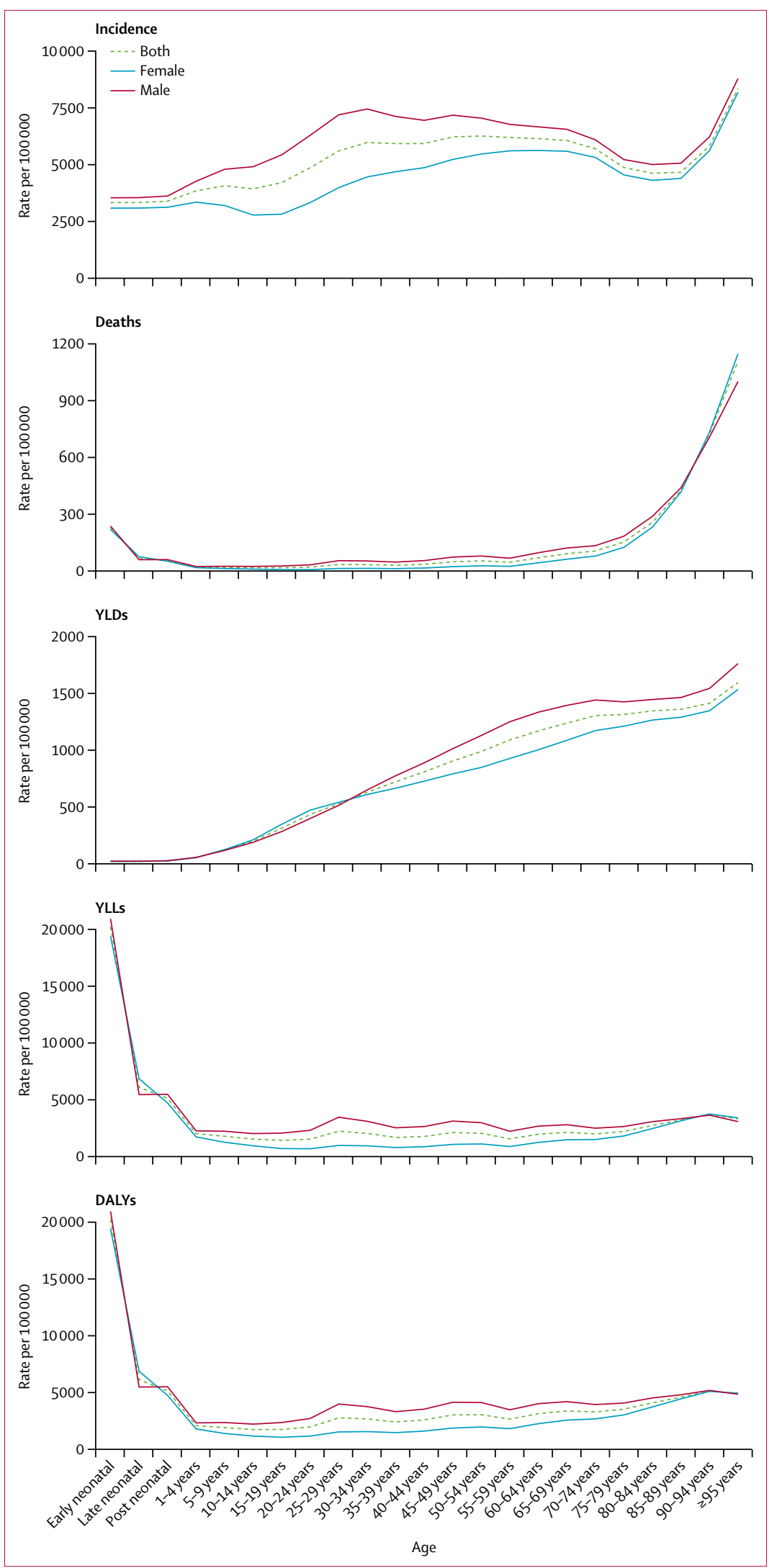


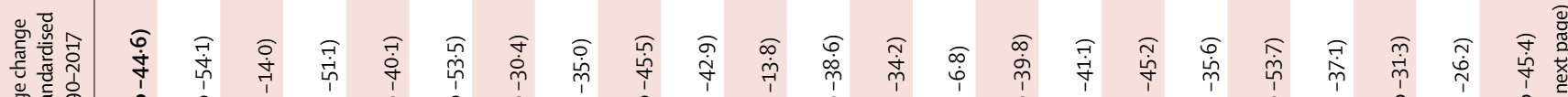

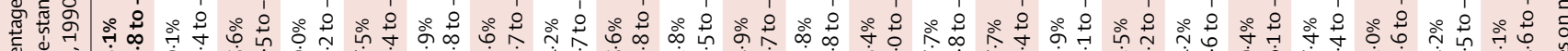

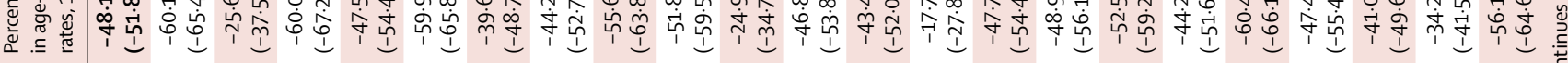

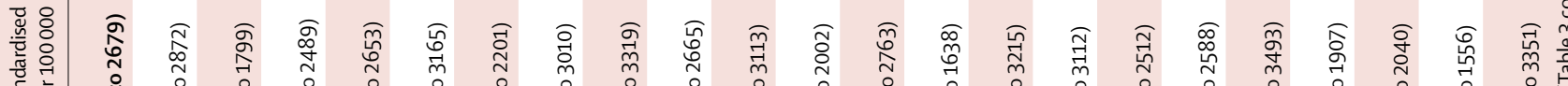

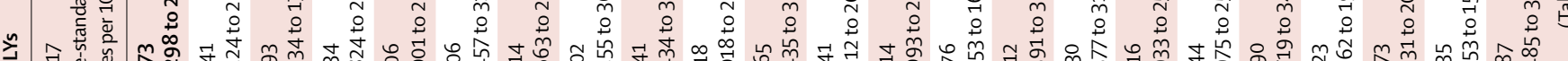

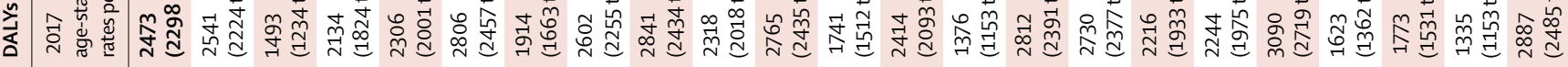

苋 芯

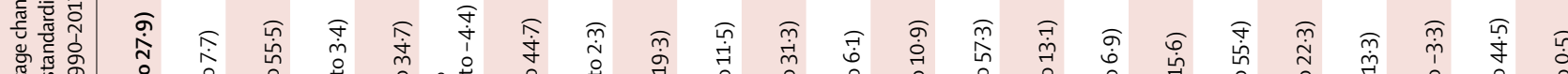

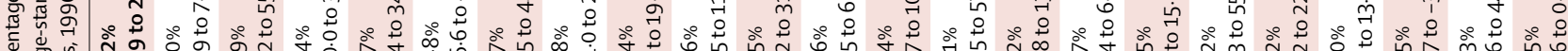

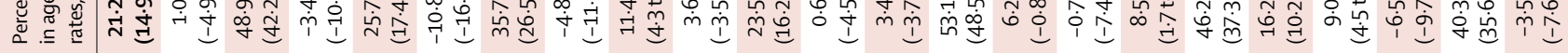

छ 8

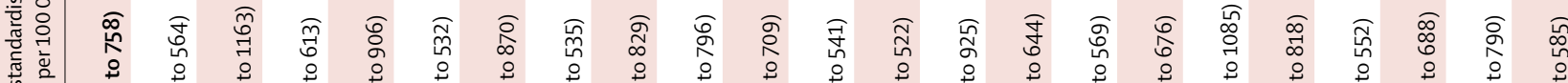

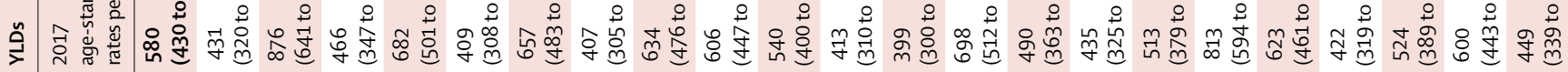

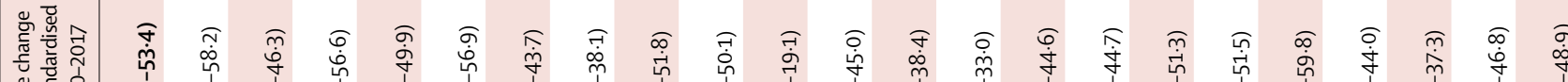

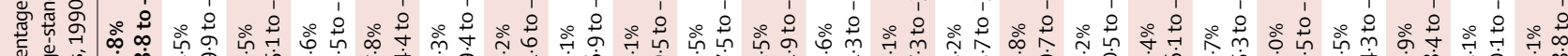

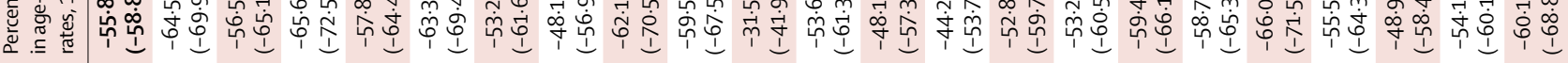

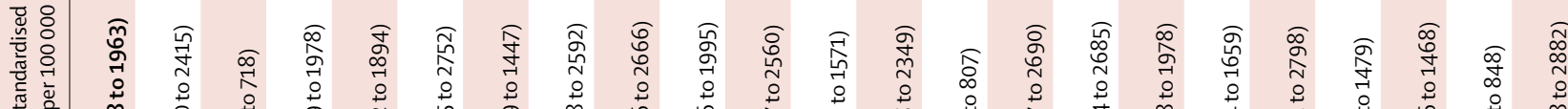

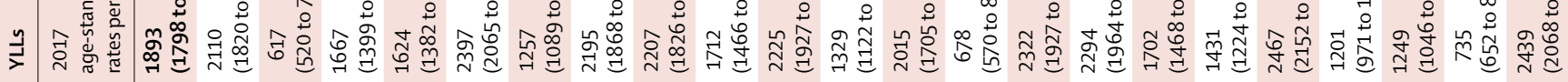

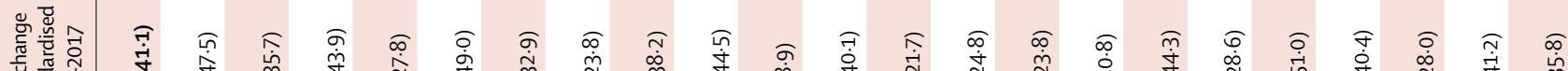

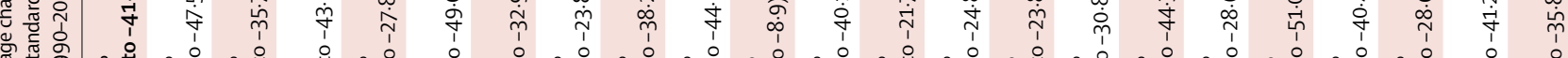

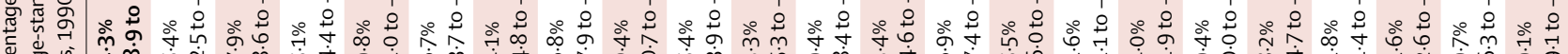

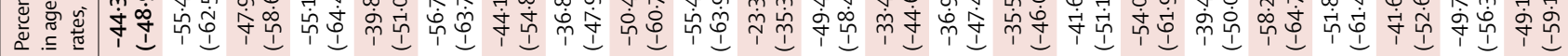

尊 8

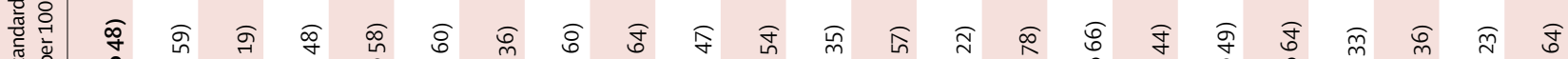

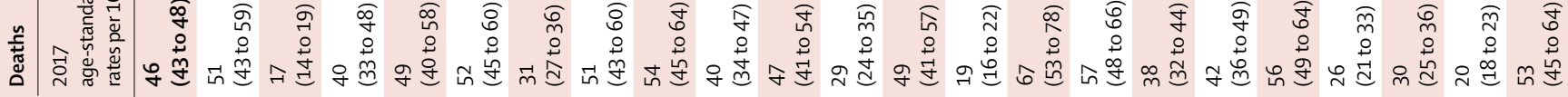

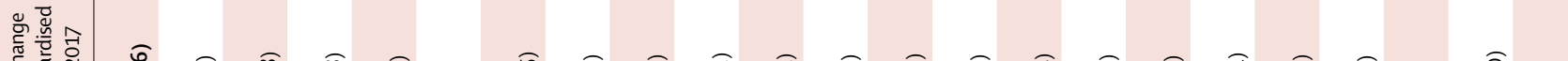

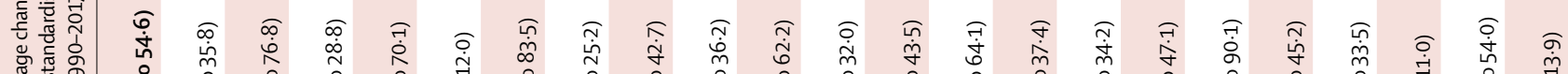

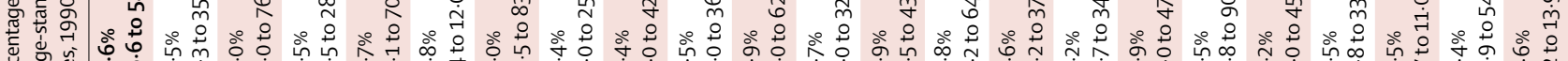

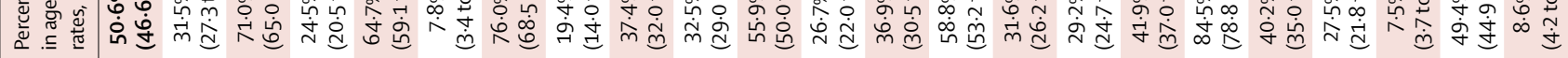

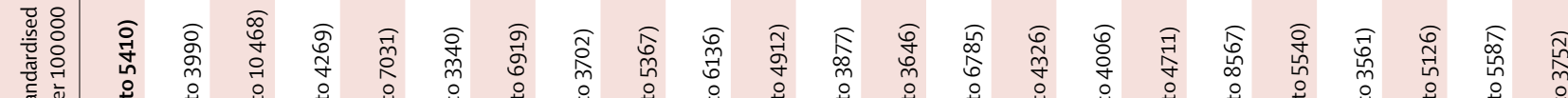

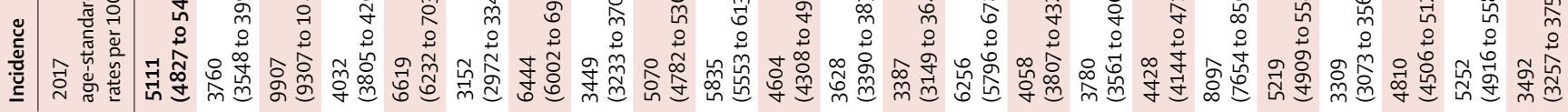

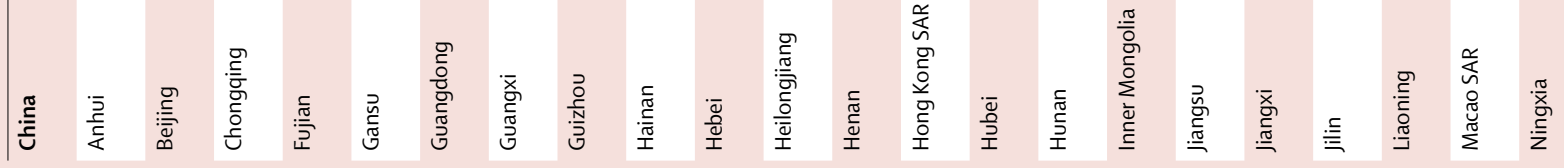




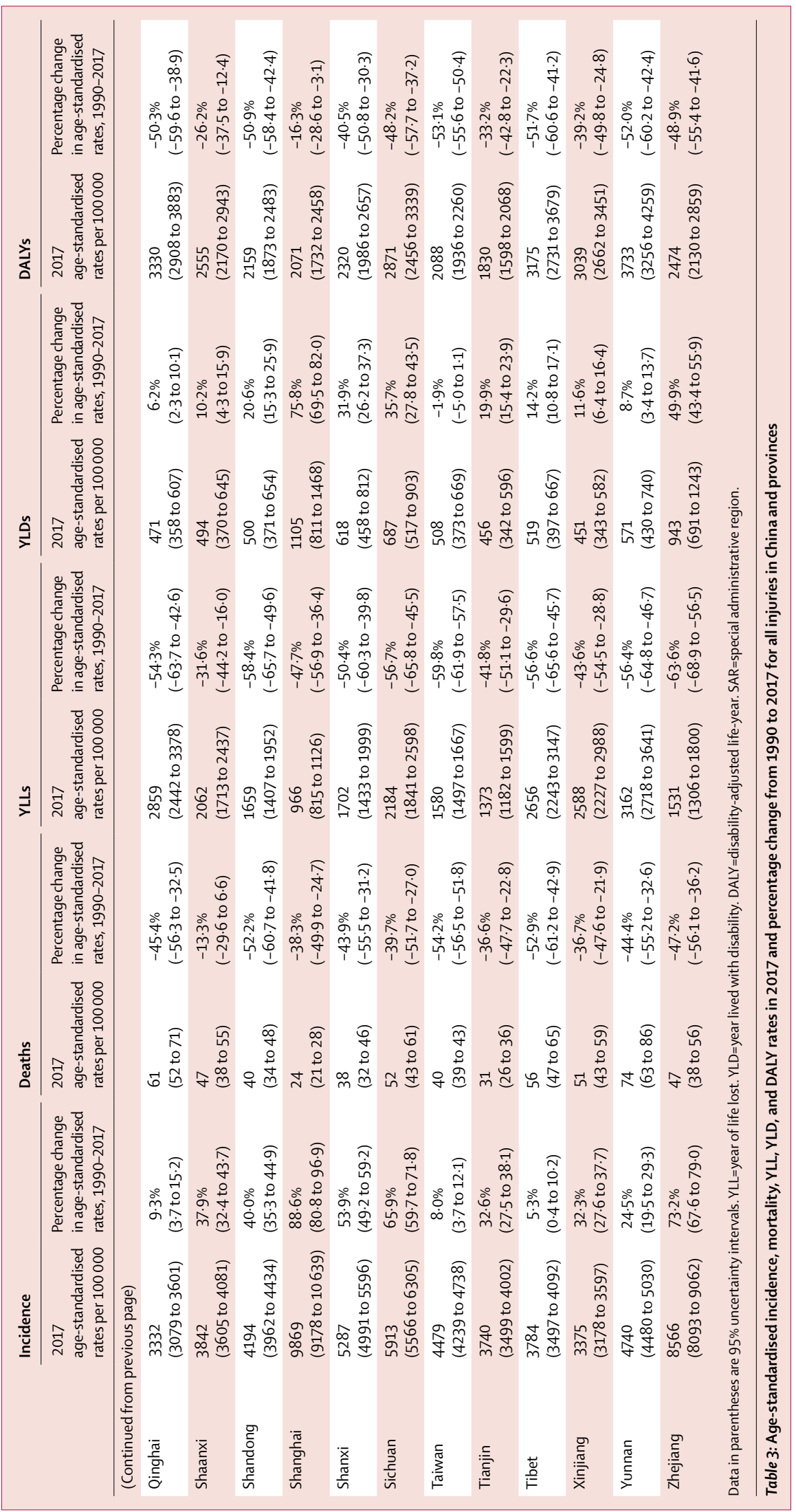



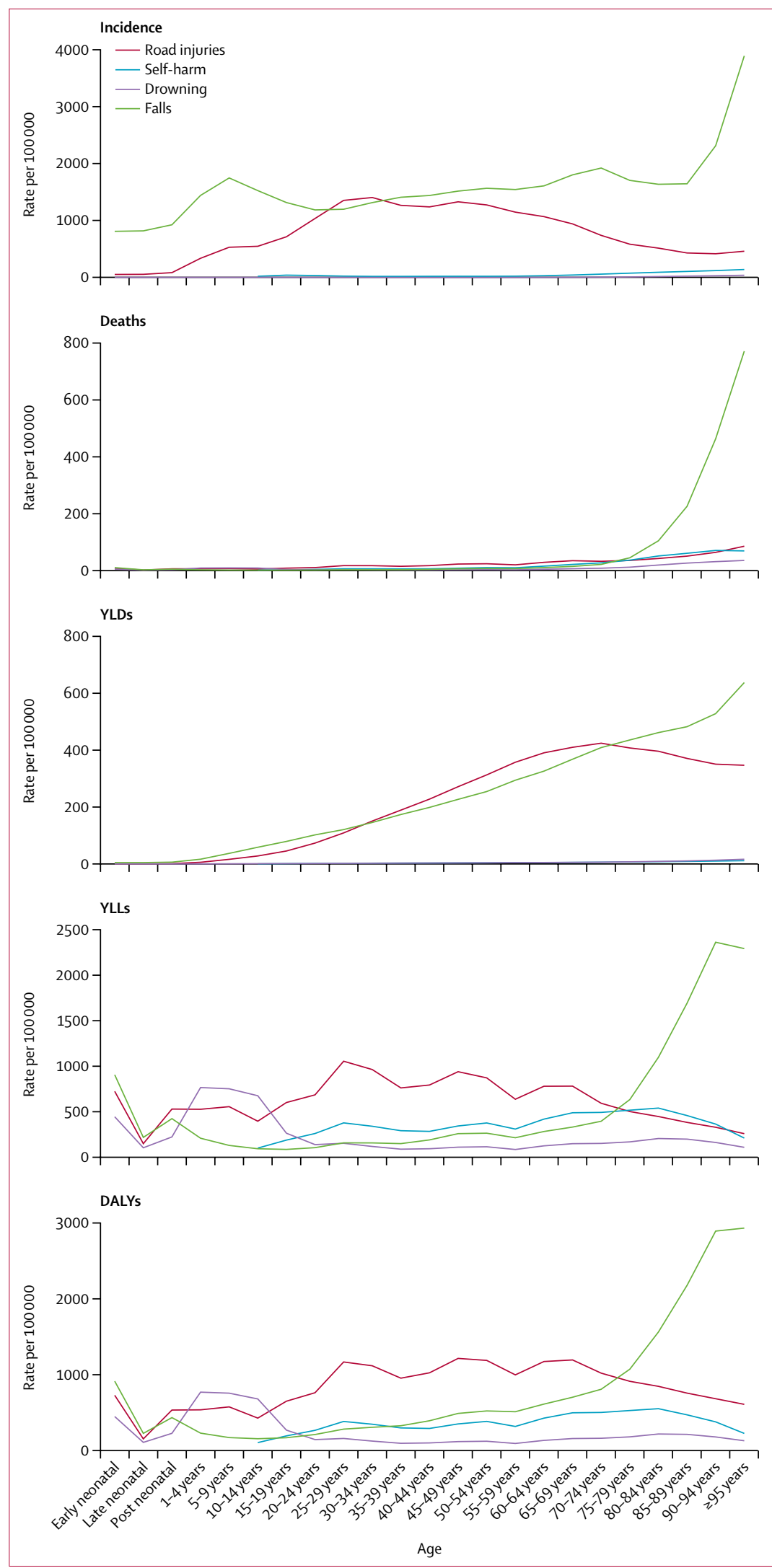

Road injuries peaked in early adulthood, were relatively stable between age ranges 25-29 and 60-69 years, and fell in the later years of life. Drowning peaked in childhood, whereas self-harm rates showed a small peak in the 25-29 years and 80-84 years age groups (figure 2). In terms of the geographical pattern of the four leading causes of age-standardised DALYs, there was a large disparity in road injuries between eastern and western districts, with the lowest rate of 294 DALYs (95\% UI 244-358) per 100000 in Hong Kong and highest rate of 1343 DALYs (1151-1615) per 100000 in the Qinghai (appendix $\mathrm{p}$ 6). The age-standardised DALY rate of falls ranged from 153 DALYs (114-221) per 100000 in Jilin to 662 DALYs (441-812) per 100000 in Yunnan (appendix p 7). For drowning, the difference in age-standardised DALYs ranged from 51 DALYs (42-65) per 100000 in Beijing to 544 DALYs (445-654) per 100000 in Xinjiang (appendix $\mathrm{p}$ 8). The highest rate of age-standardised DALYs for self-harm was in Taiwan with 542 DALYs (509-578) per 100000 and the lowest was in Beijing with 104 DALYs (81-131) per 100000 (appendix p 9).

The age-standardised incidence rate of all injuries increased by $50 \cdot 6 \%$ (95\% UI 46.6-54.6) at the national level between 1990 and 2017 (table 1). Despite the increase in age-standardised incidence, China experienced a substantial decrease in age-standardised mortality rate (44.3\% decrease, 95\% UI 41-1-48 -9) and age-standardised DALY rates $(48 \cdot 1 \%, 44 \cdot 6-51 \cdot 8)$ for all injuries between 1990 and 2017 (tables 1, 2). Age-standardised DALY rates for drowning; injuries from fire, heat, and hot substances; adverse effects of medical treatments; animal contact; environmental heat and cold exposure; self-harm; and executions and police conflict declined by more than 60\% between 1990 and 2017 (table 2).

The age-standardised incidence rate of road injuries in 2017 more than doubled, increasing by $113.2 \%$ (95\% UI $103 \cdot 7$ to $123 \cdot 6$ ) from 1990 to 2017 (table 1). However, age-standardised mortality and DALY rates from road injuries decreased by $21.8 \%(14.9$ to 30.7$)$ and $25.0 \%(18.8$ to $32 \cdot 5)$, respectively (tables 1,2$)$. Agestandardised DALY rates of road injuries varied from an increase of $9.5 \%(-10.8$ to 31.9$)$ in Shaanxi to a decrease of $63.5 \%(60.6$ to $66 \cdot 0)$ in Taiwan (appendix p 6).

The age-standardised incidence rate of falls increased by $113.2 \%$ (95\% UI 104.4 to 123.6 ) between 1990 and 2017 (table 1). The age-standardised mortality rate for falls increased by $12 \cdot 8 \%(-23.9$ to $33 \cdot 4)$, whereas the DALY rate showed no substantial change over this time period (tables 1, 2). Age-standardised DALY rates from falls decreased in 16 provinces but increased in 18 others

Figure 2: Age-specific incidence, death, YLD, YLL, and DALY rates by cause of injury in China, 2017

Self-harm is measured from age 10-14 years onwards. YLD=year lived with disability. YLL=year of life lost. DALY=disability-adjusted life-year. 


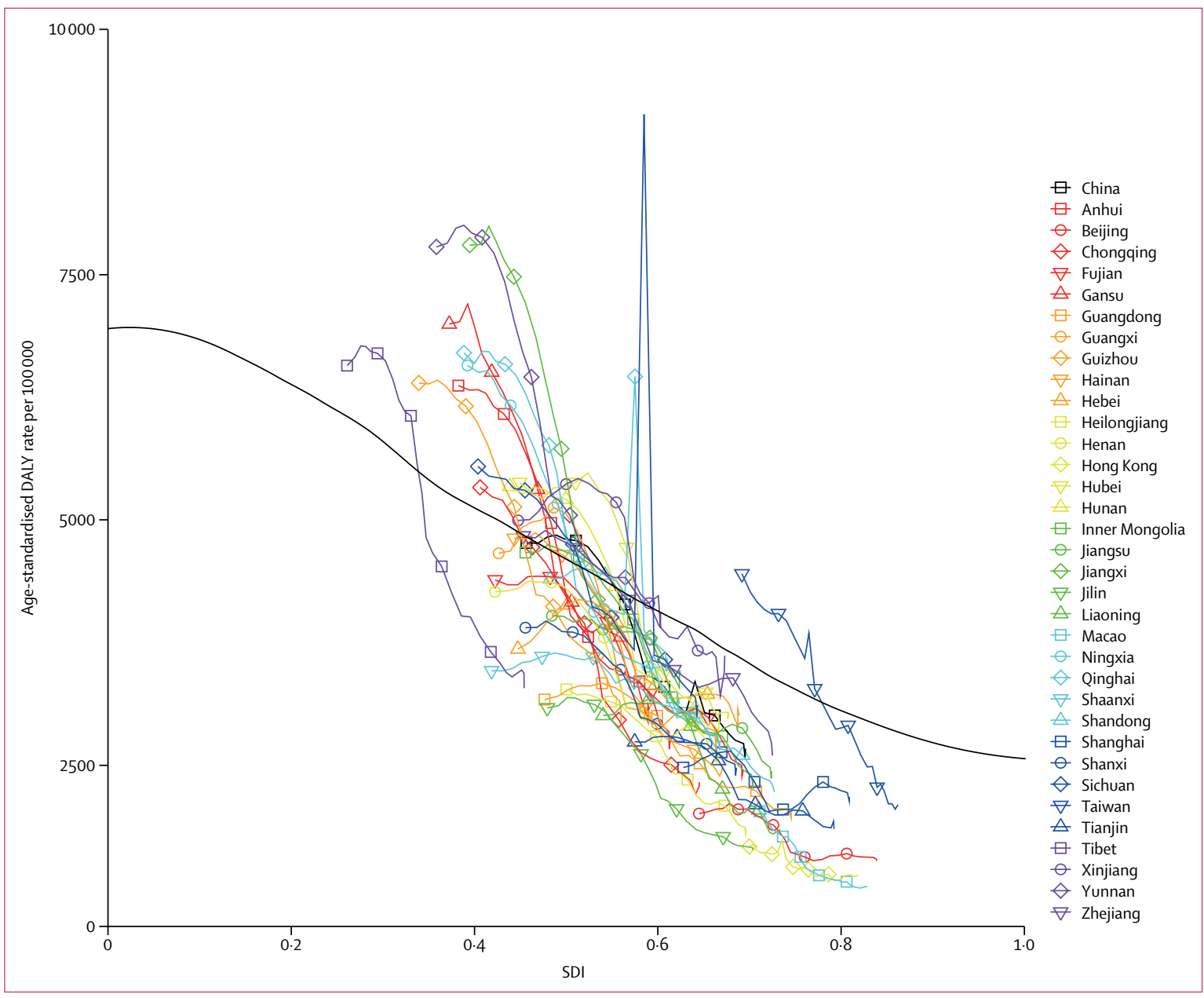

Figure 3: Age-standardised DALYs by province and SDI value

The black line shows the expected pattern of injury DALY rates with sociodemographic development based on all GBD locations. DALY=disability-adjusted life-year. SDI=Socio-demographic Index.

(appendix p 7). Tibet experienced the largest decrease $(40 \cdot 4 \%, 95 \%$ UI $22 \cdot 5$ to $53 \cdot 2)$ whereas the largest increase occurred in Shanghai $(46 \cdot 8 \%, 24 \cdot 3$ to $66 \cdot 7$; appendix p 7).

The age-standardised incidence rate of drowning decreased by $17 \cdot 4 \%(95 \%$ UI $10 \cdot 2-23 \cdot 8)$ from 1990 to 2017 (table 1). Age-standardised mortality and DALY rates decreased by $65 \cdot 3 \%(62 \cdot 9-67 \cdot 5)$ and $71 \cdot 3 \%(69 \cdot 1-73 \cdot 3)$, respectively (tables 1,2$)$. Age-standardised DALY rates decreased in all provinces, with decreases varying from $46 \cdot 9 \%(35 \cdot 8-56 \cdot 2)$ in Hong Kong to $80 \cdot 2 \%(78 \cdot 4-81 \cdot 8)$ in Taiwan (appendix p 8).

The age-standardised incidence rate of self-harm decreased by $39.4 \%(95 \%$ UI 33.8-45.1) from 1990 to 2017, while age-standardised mortality and DALY rates of self-harm decreased by $65 \cdot 6 \%$ (95\% UI 57.6-68.7) and $71 \cdot 8 \%(64 \cdot 7-74 \cdot 3)$, respectively (tables 1,2$)$. Taiwan had a $43.9 \%(95 \%$ UI $34.7-54.8)$ increase in agestandardised DALY rates, whereas 33 provinces had decreases varying from $41 \cdot 1 \%(27 \cdot 9-52 \cdot 3)$ in Hong Kong to $82 \cdot 9 \%(76 \cdot 4-86 \cdot 6)$ in Jiangxi (appendix p 9).
Relative to the expected pattern of injury DALY rates with sociodemographic development based on all GBD locations, provinces in China have shown faster decline as their SDI has increased (figure 3). In other words, between 1990 and 2017, China achieved a greater reduction in age-standardised DALY rates from injuries than the global average. Note that the sharp interruptions in the DALY rates for several provinces were due to natural disasters (eg, earthquakes in Sichuan in 2008 and in Qinghai in 2010).

\section{Discussion}

This study on the burden of injuries in China revealed that although the incidence of injuries increased between 1990 and 2017, the injury burden in terms of mortality and DALYs greatly improved. This change is not surprising for China, which has experienced a rapid social and economic development over the past three decades. On the one hand, transformation of the social economy has accelerated the process of motorisation and 
industrialisation, leading to the arrival of motorised society and environmental pollution that has dramatically increased the possibility of road injuries and has been reported as a risk factor for fall-related injury. ${ }^{15-17}$ On the other hand, the burden of fatal injury outcomes might have been reduced by the substantial socioeconomic and political developments that have occurred in the past 30 years. ${ }^{5,15}$ Of these developments, the most important were probably reduced poverty, higher employment, availability and coverage of medical and basic public health services, formulation of injury prevention-related policies and legislations, active government-supported initiatives, and increasing the injury prevention awareness of the population, particularly for child injury prevention. ${ }^{4,5}$ Child protection strategies have been widely acknowledged and publicly supported, and there has been some speculation that the one-child policy has led to greater parental attention to children, thus driving large improvements in younger age groups, given that many child injuries might be due to lack of supervision or unsafe circumstances. ${ }^{5,18}$

Economic development has a complex relationship with road injuries, as it has been reported that road injury death increases at the early stage of economic development. ${ }^{19-21}$ In low-income countries, car crashes and road injury deaths have been estimated to increase by $4.7 \%$ and $3.1 \%$, respectively, for each $10 \%$ increase in gross domestic product (GDP). ${ }^{19-21}$ In China, GDP has increased by 30 times over the past two decades, with increases of highway mileage from 1.03 to 4.36 million $\mathrm{km}$ and of motor vehicle users from 14.76 million to 25.01 million, contributing to an increased probability of road injury. ${ }^{22-24}$ However, improvements in road construction, expansion of road safety awareness, and increased motor vehicle safety systems have occurred in parallel with these economic developments, which might explain why increases in incidence were accompanied by decreases in mortality. ${ }^{25}$ Road safety laws are likely to have played a role. The Regulation of Road Traffic Management was formulated in 1988 and included requirements to use seatbelts and helmets. The Road Traffic Safety Law was then enacted in 2003 and included more stringent road traffic safety regulations pertaining to drinking and driving, speeding, lane use, and the licencing system. ${ }^{26,27}$ In addition, an inter-ministry project involving 27 government departments was established in 2003 with the purpose of improving road safety. ${ }^{28}$ Additionally, in 2011, drinking and driving and speeding became offences under criminal law in China. ${ }^{29}$ Finally, regulations targeted at road safety in the vicinity of schools, championed by ten ministries, might have contributed to the decline in burden of road injury in children. ${ }^{30}$

The burden of self-harm also greatly declined during the study period. One of the key strategies of suicide prevention has been to restrict access to the means of suicide. ${ }^{31,32}$ The Chinese Government enforced a law in 1981 to strictly control the manufacturing, sales, and use of firearms. ${ }^{33}$ Regulations enacted in 1997 and revised in 2001 also increased the supervision and management of production, marketing, and use of pesticides and other agricultural chemicals..$^{34}$ In 2005 , a regulation was enacted to reinforce the management of narcotic and psychotropic drugs to improve the safety of using these drugs. ${ }^{35}$ Moreover, the prevention of self-harm might have benefited from efforts to improve mental health services, given that a large proportion of individuals who die by suicide in China have a mental illness. ${ }^{36}$ The National Mental Health Work Plan (2015-2020), jointly issued by the National Health and Family Planning Commission, the Ministry of Civil Affairs, the Ministry of Public Security, and the China Disabled Persons' Federation, proposed a goal of improving mental health services by strengthening advocacy for mental health issues and reinforcing interventions for populations with psychological and behavioural issues. ${ }^{37}$ The first national mental health law, implemented in 2013 , included treatment standards and treatment access protections ${ }^{38}$ that led to 4.3 million people with mental health issues being registered for services, among whom $73.2 \%$ had received services by the end of $2014 .{ }^{37,39}$ The decline in suicide in females might be associated with improvements in economic equality, such as increased educational opportunities and freedom of marriage. Despite the overall improvements in the burden of selfharm, older people (ie, aged $\geq 60$ years) continue to experience considerable burden. Older people have been found to be susceptible to self-harm risk factors such as isolation and barriers to accessing health care, particularly for the so-called empty nest elderly, ${ }^{32,40,41}$ who might be prone to depression, sadness, and grief after the departure of their children and who can face substantial financial pressure when coping with chronic diseases after retirement. ${ }^{42,43}$

The burden of drowning also greatly decreased between 1990 and 2017. Since 2007, the Ministry of Education has disseminated annual warnings about the risks of drowning and advises adult supervision near bodies of water. ${ }^{44}$ This increased awareness might have partly mitigated the risk of drowning. Additionally, the enrolment rate for kindergarten has increased in the past 15 years, ${ }^{45}$ which has probably decreased the amount of exposure young children have to bodies of water. Improved infrastructure projects including bridges, roads, levees, safe drinking water, and sanitary washroom programmes are likely to have also decreased exposure to bodies of water. ${ }^{46}$ Improved waterborne traffic safety regulations have also been legislated in the past few decades, which might play a role. ${ }^{47}$

The burden of falls declined overall from 1990 to 2017, but with a notable increase in burden among older people. This is probably explained by the $8 \cdot 5$-year increase in life expectancy during the past two decades, resulting in a greater proportion of older people living with chronic diseases at risk of fall-related injuries and 
death. ${ }^{48}$ As discussed previously, the older population living without familial or social support might be at higher risk of disability or death due to delayed care and treatment for fall-related injuries..$^{40,42,49}$ Another possible factor responsible for the high burden of falls among older people could be the long-term exposure to ambient particulate matter, which has been reported as an important risk factor of fall-related injury. ${ }^{17}$ Given the high burden of falls in older people, a large economic burden of falls and fall-related injury could be reasonably anticipated, implying that more attention should be given to this looming health crisis, especially to achieve the sustainable development goals of healthy ageing. ${ }^{50}$

This research, as a part of the GBD study, included the same limitations previously discussed in GBD 2017 literature, particularly as they pertained to burden estimation in China. ${ }^{6-11}$ One of the main limitations of measuring injury burden in China was a lack of reliable injury incidence data. Although the NISS ${ }^{13}$ and the China Zhuhai injury patient follow-up study ${ }^{14}$ are important sources of injury data in China, these data are not nationally representative and data from before 2006 were unavailable. Data on injuries before 2006 could only be derived from sparse existing literature sources, which caused the modelling process for injuries to depend more heavily on cause of death estimates, covariates, and data from surrounding countries. The mortality component in terms of YLLs constituted close to $80 \%$ of injury DALYs in China and therefore DALY estimates were most sensitive to the analyses of cause of injury death data. In the 1990s and part of the 2000s, cause of death estimates were available for a sample of the country only. However, these data were considered to be representative for the provinces. It is possible that some part of the large declining trend was influenced by the lesser coverage and quality of cause of death data in the $1990 \mathrm{~s}$, but the declines recorded were so large that it is unlikely the trends we report are spurious. Moreover, data from the sample registration system in recent years aligned well with the vital registration data that achieved large increases in coverage over the past decade, ${ }^{8}$ which could also avoid the underestimation of the burden of road injuries caused by policy-reported data. ${ }^{51}$

Furthermore, as the DSP system and the NISS are the primary data sources for fatal and non-fatal injury analysis in China, the accuracy of results presented here is certainly subject to the quality and reliability of the input data from these surveillance systems. As with all vital registration and surveillance systems, issues such as misclassification and under-reporting can substantially affect outcomes based on such data. However, strict internal data quality auditing methods such as the underreporting survey done for the DSP system and other reviewing procedures at different levels of CDCs (county, precinct, provincial, and national), including crosschecking using multiple sources based on the electronic surveillance system management platforms, have been implemented to continuously improve the quality of the data from the two surveillance systems. To further improve the quality of the data from these systems, additional efforts need to be made. First, the existing training, implementation, and assessment of data quality control measures should be reinforced for all staff at all levels of institutions involved in the data collection processes of these two systems. Second, data sharing among researchers, both domestic and international, should be encouraged. Improved use of data can further help to improve the quality of data in the future. Third, more efforts could be made to adopt more advanced information technology and big data methods to bridge the gap of the available data and the best information on population health in China.

In conclusion, although the overall incidence of injuries in China has increased since 1990, the burden in terms of DALYs and cause-specific mortality has decreased, particularly among the key causes of injury, including road injury, self-harm, drowning, and falls. These patterns were probably due to the complex socioeconomic and demographic changes during this time period, which probably led to a greater number of individuals being exposed to risks such as motor vehicle accidents and falls but also led to infrastructure and health-care improvements. The trends described in this study might be useful in guiding future policy development and health-care system investments that aim to both decrease the incidence of injuries and increase the access to medical care when injuries do occur. These estimates and trends might also depict what other emerging economies should anticipate as they progress through the epidemiological transition.

Contributors

DL, WL, and TV contributed to the concept of the manuscript. YP and JY completed the first draft of the manuscript. WY, EY, DX, GX, and JC contributed to the discussion part of the manuscript. JAH, WCM-V, SLJ, ZL, and TV provided critical feedback on data analysis, results, and discussion. MSB, CNH, and MS managed the estimation process. CJLM revised the manuscript critically for important intellectual content. All authors contributed to the framework construction, results interpretation, manuscript revision, and approved the final version of the manuscript. The corresponding authors attest that all listed authors meet authorship criteria and that no others meeting the criteria have been omitted.

Declaration of interests

We declare no competing interests.

Data sharing

Additional results are available on the IHME website. For the IHME website see

Acknowledgments

This work was funded by the Bill \& Melinda Gates Foundation.

Editorial note: The Lancet Group takes a neutral position with respect to territorial claims in published maps and institutional affiliations.

References

1 Chen Z. Healthy China 2020 strategic research report. Amsterdam: Elsevier, 2015.

2 Zhou Y, Baker TD, Rao K, Li G. Productivity losses from injury in China. Inj Prev 2003; 2: 124-27.

3 Chinese Center for Disease Control and Prevention. Report on the prevention of injury in China. Beijing: People's Medical Publishing House, 2007 (in Chinese) 
4 Duan LL, Ye PP, Wang LH, Li ZX. Future challenges and solutions for safety in China: China CDC's exploration of injury prevention strategies. Glob Health J 2018; 2: 14-23.

5 Li LP, Yang JZ. Injury prevention in China: government-supported initiatives on the leading causes of injury-related deaths. Am J Public Health 2019; 4: 557-58.

6 GBD 2017 Causes of Death Collaborators. Global, regional, and national age-sex-specific mortality for 282 causes of death for 195 countries and territories, 1980-2017: a systematic analysis for the Global Burden of Disease Study 2017. Lancet 2018; 392: 1736-88.

7 GBD 2017 Disease and Injury Incidence and Prevalence Collaborators. Global, regional, and national disability-adjusted life-years for 354 diseases and injuries and healthy life expectancy for 195 countries and territories, 1990-2017: a systematic analysis for the Global Burden of Disease Study 2017. Lancet 2018; 392: 1789-858

8 GBD 2017 Mortality Collaborators. Global, regional, and national age- and sex-specific mortality and life expectancy for 195 countries and territories, 1950-2017: a systematic analysis for the Global Burden of Disease Study 2017. Lancet 2018; 392: 1684-735.

9 GBD 2017 Risk Factor Collaborators. Global, regional, and national comparative risk assessment of 84 behavioural, environmental and occupational, and metabolic risks or clusters of risks for 195 countries and territories, 1990-2017: a systematic analysis for the Global Burden of Disease Study 2017. Lancet 2018; 392: 1923-94.

10 GBD 2017 DALYs and HALE Collaborators. Global, regional, and national disability-adjusted life-years (DALYs) for 359 diseases and injuries and healthy life expectancy (HALE) for 195 countries and territories, 1990-2017: a systematic analysis for the Global Burden of Disease Study 2017. Lancet 2018; 392: 1859-922.

11 GBD 2017 Population and Fertility Collaborators. Population and fertility by age and sex for 195 countries and territories, 1950-2017: a systematic analysis for the Global Burden of Disease 2017. Lancet 2018; 392: 1995-2051.

12 Stevens GA, Alkema L, Black RE, et al. Guidelines for accurate and transparent health estimates reporting: the GATHER statement. PLoS Med 2016; 13: e1002056.

13 Duan LL, Deng X, Wang Y, et al. The National Injury Surveillance System in China: a six-year review. Injury 2015; 46: 572-79.

14 Cnossen MC, Polinder S, Vos PE, et al. Comparing health-related quality of life of Dutch and Chinese patients with traumatic brain injury: do cultural differences play a role? Health Qual Life Outcomes 2017; 15: 72 .

15 Ozanne-Smith J, Li QF. A social change perspective on injury prevention in China. Inj Prev 2018; 24 (suppl 1): i25-31.

16 Huang C, Yu H, Koplan JP. Can China diminish its burden of non-communicable diseases and injuries by promoting health in its policies, practices, and incentives? Lancet 2014; 384: 783-92.

17 Guo Y, Lin H, Shi Y, et al. Long-term exposure to ambient PM2.5 associated with fall-related injury in six low- and middle-income countries. Environ Pollut 2018; 237: 961-67.

18 Hesketh T, Lu L, Xing ZW. The effect of China's one-child family policy after 25 years. $N$ Engl J Med 2005; 353: 1171-76.

19 Ahmed N, Andersson R. Unintentional injury mortality and socio-economic development among 15-44-year-olds: in a health transition perspective. Public Health 2000; 114: 416

20 van Beeck F E, Borsboom GJ, Mackenbach JP. Economic development and traffic accident mortality in the industrialized world, 1962-1990. Int J Epidemiol 2000; 29: 503-09.

21 Bishai D, Quresh A, James P, et al. National road casualties and economic development. Health Econ 2006; 15: 65-81.

22 National Bureau of Statistics of the People's Republic of China. Statistical bulletin of the national economic and social development in 2013. Zhong Guo Tong Ji 1991; 3: 164-75.

23 National Bureau of Statistics of the People's Republic of China. Statistical bulletin of the national economic and social development of the People's Republic of China in 2013. Zhong Guo Tong Ji 2014 3: 6-14 (in Chinese).

24 Traffic Management Bureau of the Public Security Ministry. Annual report of road traffic crashes in China 2013. Beijing Traffic Management Bureau of the Public Security Ministry, 2014 (in Chinese).
25 Chi G, Wang S, Liu R. An epidemiological analysis on the relationship between road injury and traffic environment in China. Zhong hua Liu Xing Bing Xue Za Zhi 2000; 21: 330-32 (in Chinese).

26 Chi GB, Wang SY. Study on the secular trend of road traffic injuries and its influencing factors in China. Zhong hua Liu Xing Bing Xue Za Zhi 2007; 28: 148-53 (in Chinese).

27 Traffic Management Bureau of the Public Security Ministry. Law of the People's Republic of China on road traffic safety. http://www.mps.gov.cn/n2254314/n2254409/n2254431/n2254439/ c3698615/content.html (accessed July 23, 2019; in Chinese).

28 The Central People's Government of the People's Republic of China. Approval of the State Council's agreement on the establishment of Mechanism of inter-ministry co-presence conference regarding road traffic safety in the whole country. http://www.gov.cn/gongbao/content/2003/content_62529.htm (accessed June 13, 2018; in Chinese).

29 National People's Congress. Amendments to the criminal law of the People's Republic of China (VIII). http://www.npc.gov.cn/ wxzl/gongbao/2011-05/10/content_1664864.htm (accessed June 13, 2018; in Chinese)

30 Ministry of Education of the People's Republic of China. The Central People's Government of the People's Republic of China. Nursery school safety management approach. http://old.moe.gov.cn/publicfiles/business/htmlfiles/moe/ moe_621/201412/180470.html (accessed June 26, 2018; in Chinese).

31 Florentine JB, Crane C. Suicide prevention by limiting access to methods: a review of theory and practice. Soc Sci Med 2010; 70: $1626-32$.

32 WHO. Preventing suicide: a global imperative. Geneva: World Health Organization, 2014.

33 National People's Congress. Law of the People's Republic of Chin on control of guns. China's National People's Congress Network. http://www.npc.gov.cn/wxzl/gongbao/1996-07/05/ content_1479974.htm (accessed July 26, 2019; in Chinese)

34 Order of the State Council of the People's Republic of China (No. 326). Decision of the state council on amending the regulations on the administration of pesticide. http://www.gov.cn/ gongbao/content/2002/content_61560.htm (accessed June 13, 2018; in Chinese).

35 Order of the State Council of the People's Republic of China (No. 442). Regulations on the administration of narcotic drugs and psychotropic substances. http://www.gov.cn/gongbao/ content/2005/content_80524.htm (accessed June 13, 2018; in Chinese).

36 Phillips MR, Yang G, Zhang Y, Wang L, Ji H, Zhou M. Risk factors for suicide in China: a national case-control psychological autopsy study. Lancet 2002; 360: 1728-36.

37 The Central People's Government of the People's Republic of China. Circular of the general office of the State Council on forwarding the national mental health work plan of the health and family planning commission and other departments (2015 to 2020). http://www.gov.cn/zhengce/content/2015-06/18/ content_9860.htm (accessed June 13, 2018; in Chinese)

38 The Central People's Government of the People's Republic of China. The mental health law of the People's Republic of China. http://www.gov.cn/jrzg/2012-10/26/content_2252122.htm (accessed June 13, 2018; in Chinese).

39 Zhu Y, Zhang WB, Wang YF, et al. Providing free treatment for severe mental disorders in China. Shanghai Arch Psychiatry 2014; 26: 101-02.

40 Gao M, Li Y, Zhang S, et al. Does an empty nest affect elders' health? Empirical evidence from China. Int J Environ Res Public Health 2017; 14: E463.

41 Yur'yev A, Leppik L, Tooding L-M, et al. Social inclusion affects elderly suicide mortality. Int Psychogeriatr 2010; 22: 1337-43.

42 Huang RL. The family condition of empty-nest household in China. Ren Kou Yu Jing Ji 2005; 2: 57-62 (in Chinese).

43 National Center for Chronic and Noncommunicable Disease Control and Prevention, China CDC. Report on the status of elderly health: chronic disease risk factor surveillance in China. Beijing: People's Medical Publishing House, 2014 (in Chinese). 
44 Ministry of Education of the People's Republic of China. Notice of the general office of the Ministry of Education on doing a good job in preventing drowning accidents in primary and secondary school students. http://www.moe.gov.cn/srcsite/A06/ s3325/200706/t20070601_77669.html (accessed July 23, 2019; in Chinese)

45 Ministry of Education of the People's Republic of China. The education status of China in 2013. http://www.moe.gov.cn/jyb sjzl/s5990/201503/t20150331_186797.html (accessed June 13, 2018; in Chinese).

46 The Central People's Government of the People's Republic of China. Circular of the State Council on printing and distributing the outline of the development of Chinese women and the program for the development of children in China. http://www.gov.cn/ gongbao/content/2011/content_1927200.htm (accessed June 13, 2018; in Chinese).
47 Bloomberg LP, WHO. Global report on drowning: preventing a leading killer. Geneva: World Health Organization, 2014.

48 Centers for Disease Control and Prevention. Fatalities and injuries from falls among older adults, United States, 1993-2003 and 2001-2005. MMWR Morb Mortal Wkly Rep 2006; 55: 1221-24.

49 Tong HJ, Huang CY. Changes of family structure and their social influence in contemporary China. Xi Bei Ren Kou Za Zhi 2015; 6: 81-84 (in Chinese)

50 Peng K, Tian MY, Andersen M, et al. Incidence, risk factors and economic burden of fall-related injuries in older Chinese people: a systematic review. Inj Prev 2019; 25: 4-12.

$51 \mathrm{Hu}$ GQ, Baker T, Baker SP. Comparing road traffic mortality rates from police-reported data and death registration data in China. Bull World Health Organ 2011; 89: 41-45. 